\title{
Mass production of large-pore phosphorus-doped mesoporous carbon for fast-rechargeable lithium-ion batteries
}

\author{
Jinxiu Wang, Yuan Xia, Yao Liu, Wei Li*, Dongyuan Zhao* \\ Laboratory of Advanced Materials, Department of Chemistry and Shanghai Key Lab of Molecular Catalysis and Innovative Materials, iChEM and State Key \\ Laboratory of Molecular Engineering of Polymers, Fudan University, Shanghai 200433, PR China
}

\section{A R T I C L E I N F O}

\section{Keywords:}

P-doped

Mesoporous carbon

Fast charging

Mass production

Lithium-ion batteries

\begin{abstract}
A B S T R A C T
Lithium-ion batteries (LIBs) suffer from kinetic problems linked to the solid-state diffusion of Li in electrodes and commercial challenge of low cost large-scale synthesis of anode materials with custom-designed nanostructures. Here, we report a facial method for mass production of P-doped mesoporous carbons that exhibit excellent electrochemical performances as anode materials for LIBs. Hydrophobic tricresyl phosphate is explored to enlarge the pore sizes from 3.6 to $14.2 \mathrm{~nm}$, expand the interlayer spacing from 3.68 to $3.79 \AA$, and increase the graphitization degree of carbon framework with a heavy P content up to 1.90 at. \% and small domain sizes. As a result, a high reversible capacity of $\sim 500 \mathrm{~mA} \mathrm{~h} \mathrm{~g}^{-1}$ after 200 cycles at $0.5 \mathrm{C}$ is obtained, which is much higher than that of pristine mesoporous carbon and commercial graphite anode. More importantly, the resultant P-doped mesoporous carbons show a fast-charging capacity of $236 \mathrm{~mA} \mathrm{~h} \mathrm{~g}^{-1}$ at $8 \mathrm{C}$ and stable longterm cycle life over 10,000 cycles at $10 \mathrm{Ag}^{-1}$.
\end{abstract}

\section{Introduction}

Lithium-ion batteries (LIBs) have been widely used as the major power supplier for portable electronic devices [1,2]. Currently, the commercialized graphite anode cannot meet the increasing demands of rapidly developing LIBs markets due to its low theoretical specific capacity $\left(372 \mathrm{~mA} \mathrm{~h} \mathrm{~g}^{-1}\right)$. Various nanostructured $\mathrm{Si}$, Sn and transition metal oxides with ultra-high theoretical capacities have recently been explored as anode materials for LIBs [3-7]. Unfortunately, the large voltage hysteresis and huge volume expansion that occur in these materials during the $\mathrm{Li}^{+}$insertion and extraction process severely limit their extensive applications. Alternatively, a number of nanostructured carbon materials such as graphene, carbon nanotubes and porous carbon materials have been developed to increase the energy and power densities [8-11]. Particularly, the creation of porosity in carbon materials is promising to solve the known kinetic problems linked to the ion transport and solid-state diffusion of Li in electrodes [12-15]. Since the pore channels can not only increase the density of active sites with high accessibility but also facilitate the transport of electrolytes, the nano-sized carbon wall greatly shortens the diffusion length of $\mathrm{Li}^{+}$ ions and offers an ultrahigh way for electron transfer. However, most common porous carbons usually have the pore size smaller than $4.0 \mathrm{~nm}$, larger pores are highly desired for efficient energy storage especially in fast charging LIBs [16-20]. The regular method to fabricate large pores is the use of lab-made templates (i.e., highmolecular-weight block copolymers), which is unsuitable for mass production due to the complicated preparation procedure and the expensive agents. Therefore, producing large pore carbon anodes, especially with fascinating mesoporous structures such as uniform mesopores and high surface areas, in a commercially viable way is still of great challenge.

The introduction of heteroatom (e.g., N, B, S) has also been widely explored to tailor the electronic and chemical properties of carbon materials, which can further create more active sites and increase the electrode/electrolyte affinity, thereby improving the $\mathrm{Li}^{+}$storage properties [21-27]. Compared to the widely studied N doping, phosphorus has the same number of valence electrons as $\mathrm{N}$ but with larger atomic radius and higher electron-donating ability, which is of great interest to synthesize P-doped carbon materials for energy applications [28-30]. For example, Yu and coworkers fabricated phosphorus-doped ordered mesoporous carbon through a nanocasting method by using mesoporous silica (SBA-15) as a hard template. The obtained materials showed excellent electrocatalytic activity for oxygen reduction reaction (ORR) in fuel cells [31]. Hou and coworkers synthesized phosphorus-doped graphene by thermal annealing of GO and triphenylphosphine (TPP), which exhibited highly enhanced electrochemical properties in LIBs and ORR, benefiting from the phosphorus doping that can induce a large number of defects [32]. However, the synthesis strategies usually

\footnotetext{
* Corresponding authors.

E-mail addresses: weilichem@fudan.edu.cn (W. Li), dyzhao@fudan.edu.cn (D. Zhao).
} 
turned out to be complicated, time-consuming, or expensive. Besides, it is difficult to achieve fine control of the properties in terms of surface area, large pore size, and phosphorus doping, especially in large scale production. Therefore, it is highly desirable and significant to develop a facial method to synthesize mesoporous heteroatom-doped carbon materials for high performance LIBs.

Here, we report facile mass production of P-doped mesoporous carbons with a high $\mathrm{P}$ content and large pore size via the evaporation induced self-assembly method, in which tricresyl phosphate is used as a phosphorus precursor, phenolic resol as a carbon precursor, triblockcopolymer F127 as a soft template, and cheap and scalable polyurethane (PU) foam as a macrostructure sacrificial template. The obtained P-doped mesoporous carbons are consisted of small wellorganized and interconnected nanoparticles (10-20 nm), exhibiting large tunable mesopore sizes $(6.6-14.2 \mathrm{~nm})$, high surface areas (338$630 \mathrm{~m}^{2} \mathrm{~g}^{-1}$ ), and high P contents (up to 1.90 at. \%). It is worthy to note that the mesopore size and the $\mathrm{P}$ content can be well controlled by simply changing the amounts of tricresyl phosphate. When evaluated as anodes for LIBs, these materials deliver superior performances for electrochemical storage of lithium in terms of high reversible capacity above $500 \mathrm{mAh} \mathrm{g}^{-1}$ after 200 cycles at $0.5 \mathrm{C}$, excellent rate capabilities and stable long-term cycle life up to 10,000 cycles at high rate of $10 \mathrm{Ag}^{-1}$.

\section{Experimental}

\subsection{Chemicals}

PU foam was purchased from the Shanghai Gaoxin Foam Factory. The triblock poly(ethylene oxide)- $b$-poly(propylene oxide)- $b$-poly(ethylene oxide) copolymer Pluronic F127 was purchased from Aldrich. Tricresyl phosphate, phenol, formaldehyde solution (37 wt \%), hydrochloric acid, sodium hydroxide, ethanol were supplied by the Shanghai Chemical Co. Ltd. All chemicals were used as received without further purification.

\subsection{Large-scale synthesis of P-doped mesoporous carbons}

In a typical synthetic procedure, $50.0 \mathrm{~g}$ of $\mathrm{F} 127$ was added into $500.0 \mathrm{~g}$ of ethanol and stirred for $2 \mathrm{~h}$ at $35^{\circ} \mathrm{C}$ to afford a clear solution. $250.0 \mathrm{~g}$ of $20 \mathrm{wt} \%$ ethanolic solution of resol prepared as previously reported was added into the above solution [33], the mixture was further stirred for $1 \mathrm{~h}$ at room temperature. After that, a certain amount of tricresyl phosphate was slowly added into the mixture and stirred for another $1 \mathrm{~h}$. The final homogeneous solution was coated onto $5.0 \mathrm{~g}$ of PU foam and underwent ethanol evaporation at room temperature for $5-8 \mathrm{~h}$. After the polymerization at $100^{\circ} \mathrm{C}$ for $48 \mathrm{~h}$, the as-made products were obtained. Lastly, carbonization was carried out in a tubular furnace at $850{ }^{\circ} \mathrm{C}$ for $3 \mathrm{~h}$ under $\mathrm{N}_{2}$ to get the phosphorusdoped mesoporous carbons, denoted as PMC-x, where $\mathrm{x}$ represented the mole ratio of tricresyl phosphate to phenol. The heating rate was $1^{\circ} \mathrm{C} \mathrm{min}^{-1}$ below $600{ }^{\circ} \mathrm{C}$ and increased to $5^{\circ} \mathrm{C} \mathrm{min}^{-1}$ above $600{ }^{\circ} \mathrm{C}$. For comparison, pristine ordered mesoporous carbon, denoted as OMC, was also prepared according to the above procedures.

\subsection{Characterization}

Transmission electron microscopy (TEM) and energy dispersive spectrometer (EDS) mapping images were performed on a JEM-2100F microscope (Japan) operated at $200 \mathrm{kV}$. The ground samples for TEM and EDS measurements were suspended in ethanol and supported onto carbon-coated copper grids. Field-emission scanning electron microscopy (FESEM) images were collected on the Hitachi Model S-4800 field emission scanning electron microscope. $\mathrm{N}_{2}$ sorption isotherms were measured with a Micromeritics Tristar 3020 analyzer at $-196^{\circ} \mathrm{C}$. Before the measurements, all samples were degassed at $180^{\circ} \mathrm{C}$ in vacuum for at least $6 \mathrm{~h}$. The Brunauer-Emmett-Teller (BET) method was used to calculate the surface areas $\left(\mathrm{S}_{B E T}\right)$ by using the adsorption data at $\mathrm{p} / \mathrm{p}_{0}$ of $0.02-0.2$. The total pore volume $\left(\mathrm{V}_{t}\right)$ was estimated from the adsorbed amount at $\mathrm{p} / \mathrm{p}_{0}$ of 0.995 . The micropore surface area $\left(\mathrm{S}_{\text {Micro }}\right)$ was calculated by using $t$-plot method with a relative pressure $\mathrm{P} / \mathrm{P}_{0}$ of $0.2-0.4$. The pore size $\left(\mathrm{D}_{p}\right)$ distributions were derived from the adsorption branches of isotherms by using the Barrett-Joyner-Halenda (BJH) model. X-ray photoelectron spectroscopy (XPS) was conducted on a RBD upgraded PHI-5000C ESCA system (Perkin Elmer) with an $\mathrm{Al} \mathrm{Ka}$ radiation $(14 \mathrm{kV}, 250 \mathrm{~W})$ under a pressure of $5 \times 10^{-8} \mathrm{~Pa}$. All binding energies (B. E.) were calibrated by using the containment carbon C1s peak at B.E. of $284.6 \mathrm{eV}$ as a reference. Raman spectra were recorded using micro-Raman spectroscopy (Renishaw inVia Reflex, excited by $633 \mathrm{~nm}$ He-Ne red laser, Britain). X-ray diffraction (XRD) patterns were recorded on a Bruker D8 X-ray diffractometer with Nifiltered $\mathrm{Cu} \mathrm{Ka}$ radiation at $40 \mathrm{kV}$ and $40 \mathrm{~mA}$ (Germany). The smallangle X-ray scattering (SAXS) measurements were collected on a Nanostar U SAXS system (Germany) using $\mathrm{Cu} \mathrm{Ka}$ radiation at $40 \mathrm{kV}$ and $35 \mathrm{~mA}$. The thermal decomposition behavior of the samples was monitored by using a Mettler Toledo TGA-SDTA851 analyzer (Switzerland) from 25 to $900{ }^{\circ} \mathrm{C}$ with a heating rate of $5{ }^{\circ} \mathrm{C} \mathrm{min}{ }^{-1}$.

\subsection{Electrical measurements}

The electrical measurement was carried out using homemade typical coin-type cells with lithium metal as the counter and reference electrodes at room temperature. The working electrode consisted of active material, conductivity agent (carbon black, Super-P), and polymer binder (polyvinylidene difluoride, PVDF, Aldrich) in a weight ratio of around 80:10:10. The electrolyte was $1 \mathrm{M} \mathrm{LiPF}_{6}$ in a 50:50 (w/w) mixture of ethylene carbonate and dimethyl carbonate. Cell assembly was carried out in an Ar-filled glovebox with the concentrations of moisture and oxygen below $1 \mathrm{ppm}$. Cyclic voltammograms (CV) tests were performed on CHI 660E electrochemical workstation at a sweep rate of $0.2 \mathrm{mV} \mathrm{s}^{-1}$ between $0-3 \mathrm{~V}$. The charge/discharge tests were measured on a LAND multi-channel battery testing system at different current rates (where $1 \mathrm{C}=372 \mathrm{~mA} \mathrm{~g}^{-1}$ ) within a voltage range of 0.01 $3 \mathrm{~V}$ vs. $\mathrm{Li} / \mathrm{Li}^{+}$at room temperature. The electrochemical spectroscopy (EIS) was measured in the same equipment within the frequency of 0.01 to $100 \mathrm{KHz}$. The galvanostatic intermittent titrations (GITT) were employed at a pulse of $0.1 \mathrm{~mA}$ for $10 \mathrm{~min}$ and with $30 \mathrm{~min}$ interruption between each pulse. The electrical conductivity was measured by employing a four-probe method.

\section{Results and discussion}

This process affords low-cost kilogram-scale synthesis of nanocarbon anodes (Fig. 1a). The obtained PMCs well preserve the foam-like monolithic morphology with a 3D interconnecting macrocellular network similar to that of the PU scaffolds, indicating a faithful replication (Fig. 1b and S1). Field-emission scanning electron microscopy (FESEM) image reveals that the PMC-1.2 is highly porous structure made up of small interconnected nanoparticles (Fig. 1c). The transmission electron microscopy (TEM) image further confirms the mesoporous structure with worm-like channels (Fig. 1d). The domain size is estimated to be $\sim 20 \mathrm{~nm}$, in accordance with the FESEM results. Such small domain size can shorten the diffusion length of $\mathrm{Li}^{+}$ions during the insertion and extraction. High-resolution TEM (HRTEM) image reveals a turbostratic graphite-like nature (Fig. 1e), suggesting the typical hard carbon structure of resol-derived carbon. The scanning TEM (STEM) and corresponding energy dispersive X-ray spectroscopy (EDS) elemental mapping images exhibit that $\mathrm{P}, \mathrm{C}, \mathrm{O}$ atoms are homogeneously distributed throughout the whole area (Fig. 1d), suggesting the successful doping of $\mathrm{P}$ atoms in the carbon frameworks. Similar nanostructure can also be observed in the case of PMC-0.4 and PMC-0.8 (Fig. S2). It is worth noting that the grain size gradually grows 

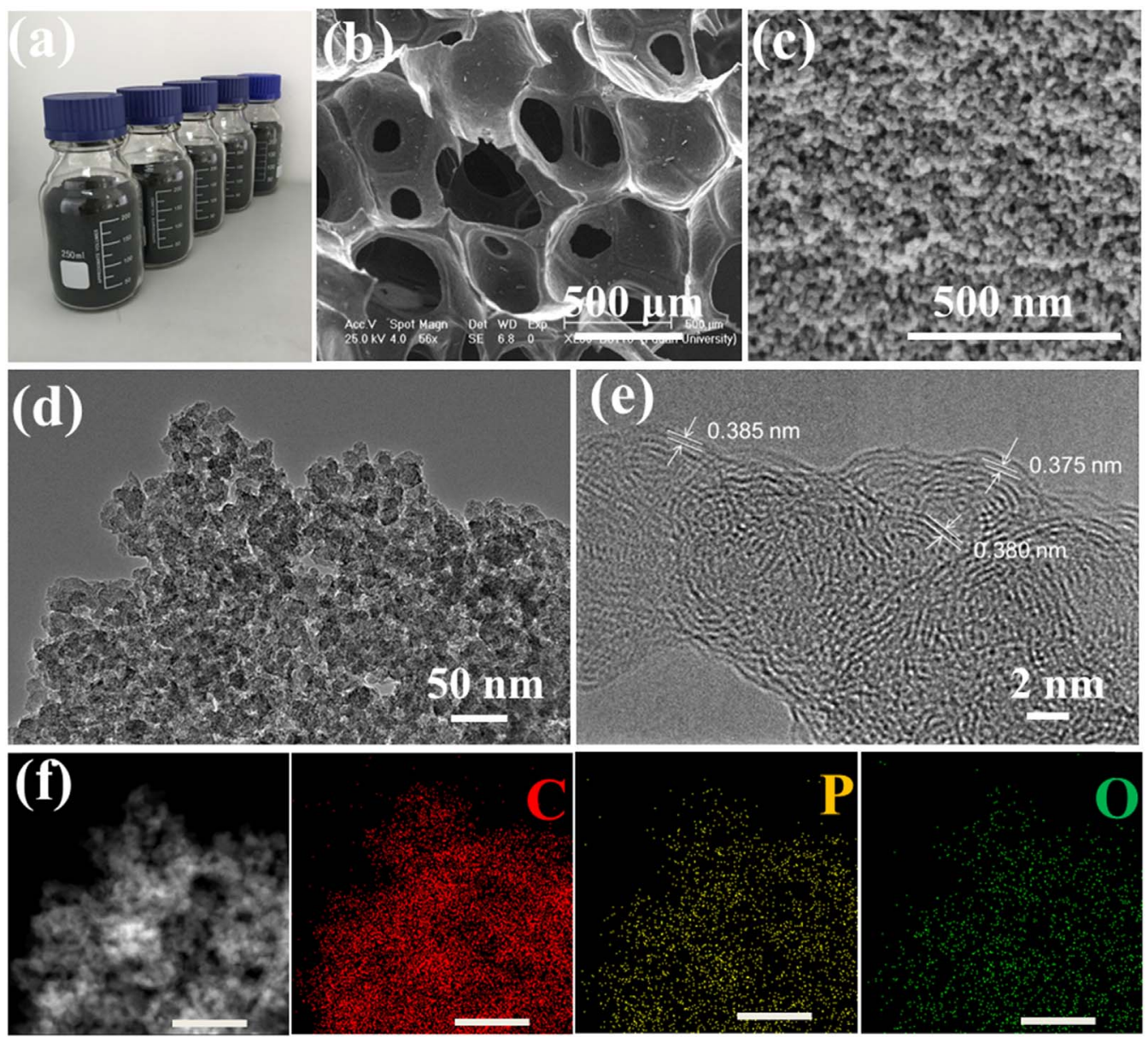

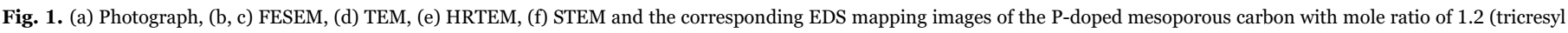
phosphate/phenol) (PMC-1.2), all scale bars in (f) are $100 \mathrm{~nm}$.

larger from 15 to $20 \mathrm{~nm}$ with the increase of tricresyl phosphate amount, at the same time the mesostructure would be disordered. Unlike the highly disordered graphenic layers in the pristine ordered mesoporous carbon, PMCs comprise curved graphenic layers stack into turbostratic nanodomains. It confirms that the P-doping facilitates more curvature in the carbons (Fig. S3) [34,35].

$\mathrm{N}_{2}$ sorption isotherms of all PMC samples show typical type-IV curves with sharp capillary condensation steps and $\mathrm{H}_{2}$-type hysteretic loops, similar to the pristine mesoporous carbon (Fig. 2a). It should be noted that the capillary condensation step shifts to high relative pressure ranges with increasing the content of tricresyl phosphate, indicating that the mesopore size becomes larger from 3.6 to $14.2 \mathrm{~nm}$ (Fig. 2b). In contrast, the specific surface area decreases from 678 to $338 \mathrm{~m}^{2} \mathrm{~g}^{-1}$ (Table S1).

The chemical compositions of the PMCs were investigated by X-ray photoelectron spectroscopy (XPS). All samples show four peaks at 133, 189, 284 and $532 \mathrm{eV}$, indicating the presence of $\mathrm{P}, \mathrm{C}$ and $\mathrm{O}$ element without any other impurities (Fig. S4). The P doping content is $~ 1.04$, 1.33 and 1.90 at. \% for PMC-0.4, PMC-0.8 and PMC-1.2, respectively. The $\mathrm{P} 2 \mathrm{p}$ high resolution spectrum of the PMC-1.2 (Fig. 2c) can be deconvoluted into two peaks at 132.7 and $133.8 \mathrm{eV}$ corresponds to the $\mathrm{P}-\mathrm{C}$ and P-O bonding, respectively $[31,36]$. The increased oxygen content in the PMC samples from 10.01 to 13.37 at\% further confirms successful incorporation of $\mathrm{P}$ in the carbon framework (Table S1).

Raman spectra of all PMC samples display two characteristic peaks located at around 1590 (G-band) and $1350 \mathrm{~cm}^{-1}$ (D-band), which correspond to the vibrations of $\mathrm{sp}^{2}$-bonded carbon atoms in graphitic carbons $\left(\mathrm{E}_{2 \mathrm{~g}}\right)$ and the disorder features in graphite material, respectively (Fig. 2d) $[37,38]$. The intensity ratio of $D$ and $G$ band $\left(I_{D} / I_{G}\right)$ for
PMC-0.4, PMC-0.8 and PMC-1.2 is calculated to be 1.33, 1.37 and 1.49 , which is larger than that of the pristine mesoporous carbon (1.29), indicating more defects caused by P-doping. The wide-angle Xray diffraction (XRD) patterns exhibit two broad peaks at about $24^{\circ}$ and $44^{\circ}$, corresponding to the (002) and (100) diffraction planes of the disordered graphitic carbon structure (Fig. 2e). It is clear to see that the 002 diffraction peak of the PMCs shifts to lower angles compared to the pristine ordered mesoporous carbon. The corresponding $d_{002}$ values are calculated to be 3.74, 3.75, $3.79 \AA$ for PMC-0.4, PMC-0.8 and PMC1.2 , respectively, which are larger than that of the pristine one (3.68 $\AA$ ). The results suggest that the interlayer spacing can be enlarged by the Pdoping, in good agreement with the HR-TEM observations, which are very favorable for $\mathrm{Li}^{+}$ion diffusion and storage $[39,40]$.

Thermogravimetric (TG) curves of the as-made P-doped samples show two stages of large weight losses (Fig. 3d). The first one from 200 to $300{ }^{\circ} \mathrm{C}$ corresponds to the decomposition of tricresyl phosphate and partial decomposition of the PU foam scaffold (Fig. S5). The second from 300 to $400{ }^{\circ} \mathrm{C}$ can be attributed to the decomposition of F127 and PU foam (Fig. S5), as well as the pyrolysis of the polymer frameworks. The carbonization yields are calculated to be about 34,38 and $33 \mathrm{wt} \%$ for PMC-0.4, PMC-0.8 and PMC-1.2, respectively.

The possible formation mechanism for low cost large-scale synthesis of large pore P-doped mesoporous carbons is illustrated in Scheme 1. First, an ethanol solution containing tricresyl phosphate, resol and F127 is impregnated into the skeletal network of PU foam which acts as a cheap and sacrificial substrate. It provides plentiful interfaces for selfassembly of the mesostructure, enabling kilogram-scale production per batch. During the solvent evaporation process, tricresyl phosphate can be accommodated into the hydrophobic PPO segments of the F127. 
(a)

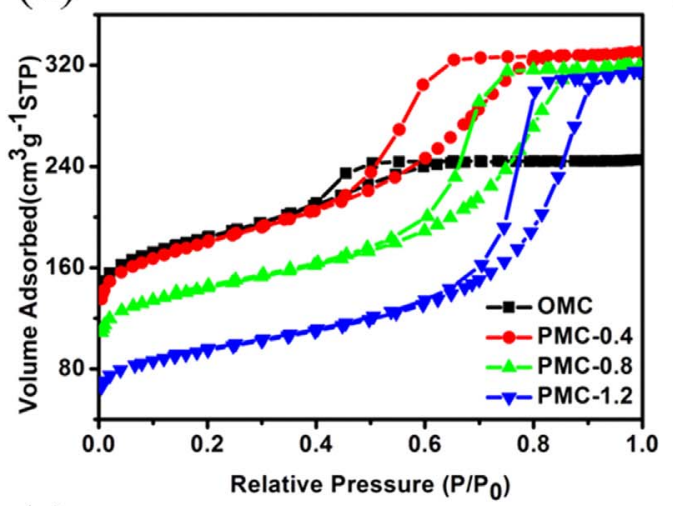

(c)

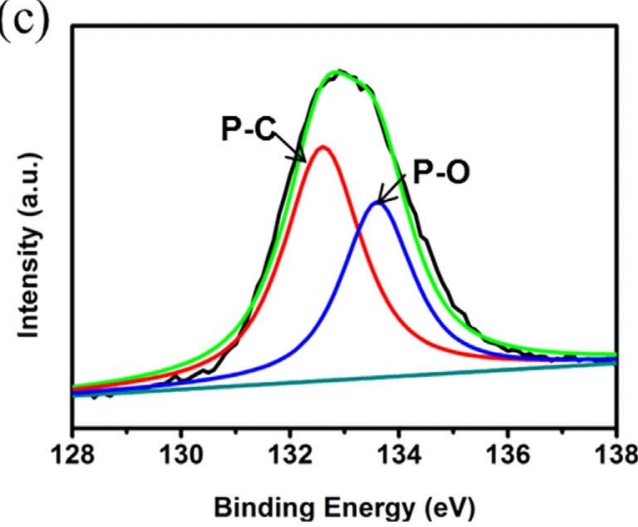

(b)

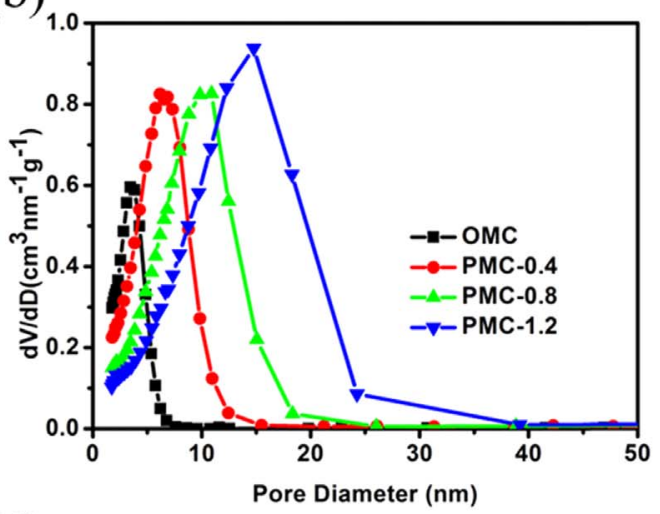

(d)

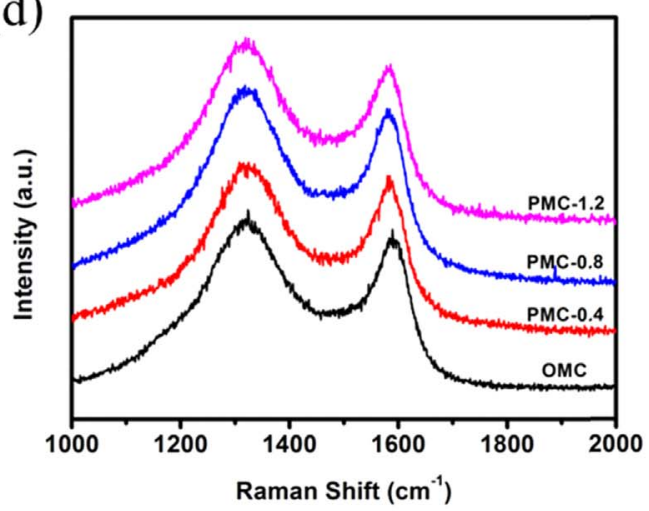

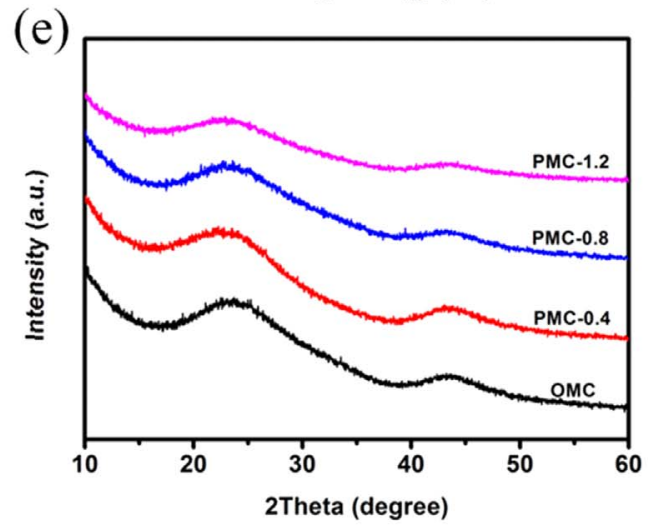

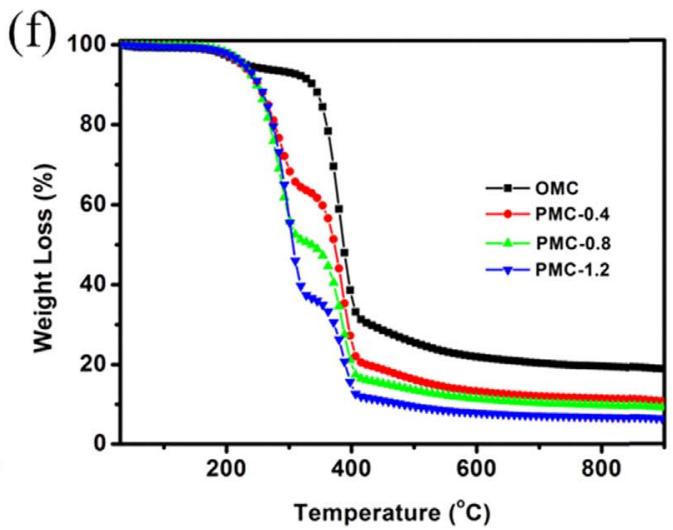

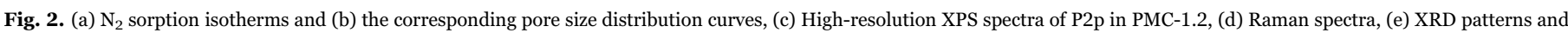

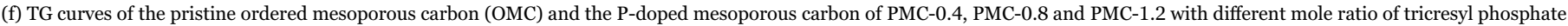
to phenol.

Meanwhile, resol molecules favor the incorporation with hydrophilic PEO blocks of Pluronic F127 due to the strong hydrogen bonding interactions. It prevents the macrophase separation of the hydrophilic resol and hydrophobic phosphorus precursors, ensuring the formation of TCP-F127-resol composite micelles. Then the micelles aggregate and assemble on the surface of the PU foam struts. The formed mesostructure can be further fixed as a result of the cross-linking and polymerization of resol during the thermopolymerization process. The small-angle X-ray scattering (SAXS) measurements clearly reveal only one broad weak peak for the as-made samples, indicating that tricresyl phosphate can assemble with the F127 and resol, but leads to a disordered mesostructures (Fig. S6). Lastly, pyrolysis at $850^{\circ} \mathrm{C}$ is carried out to remove the F127 copolymer and PU foam scaffold as well as carbonize the polymer framework. During this process, the tricresyl phosphate would be decomposed, resulting in larger mesopores than that of the pristine mesoporous carbon and incorporating $\mathrm{P}$ into the carbon framework.

\subsection{Electrochemical properties}

The electrochemical performances of the PMCs were evaluated by using the half-cell configuration and the pristine mesoporous carbon was used as a control. The cyclic voltammograms (CVs) were first performed at a scan rate of $0.2 \mathrm{mV} \mathrm{s}^{-1}$ in the voltage range of $0-3.0 \mathrm{~V}$ versus $\mathrm{Li} / \mathrm{Li}^{+}$(Fig. 3a) In the first cathodic scan, a reduction peak is observed at $\sim 0.63 \mathrm{~V}$, attributing to the formation of a solid electrolyte interface (SEI) film $[41,42]$. In the anodic scan, two broad oxidation peaks are observed at about 0.2 and $1.2 \mathrm{~V}$, which are ascribed to the lithium extraction from the graphitic layers and the defects such as pores, vacancies, edges and corners of the graphitic layers, respectively [43]. It is worthy to note that the peak at $1.2 \mathrm{~V}$ becomes stronger with increasing $\mathrm{P}$ content (Fig. S7). The galvanostatic charge-discharge profile of PMC-1.2 sample in the $1^{\text {st }}, 2^{\text {nd }}, 10^{\text {th }}, 50^{\text {th }}$ and $100^{\text {th }}$ cycle was measured at $0.2 \mathrm{C}$ (Fig. $3 \mathrm{~b}$ ). It is obvious that the PMC-1.2 electrode delivers high initial discharge and charge specific capacities 


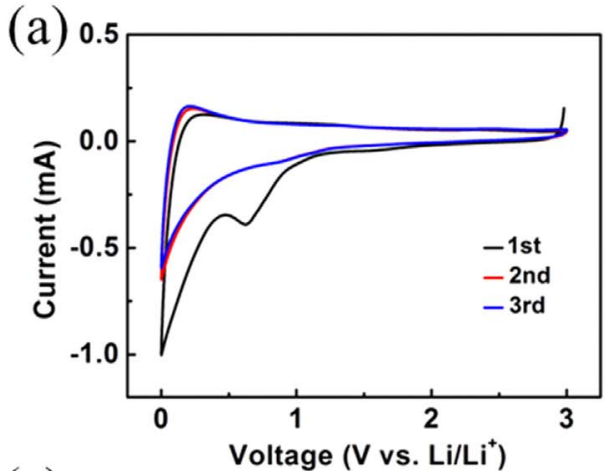

(c)

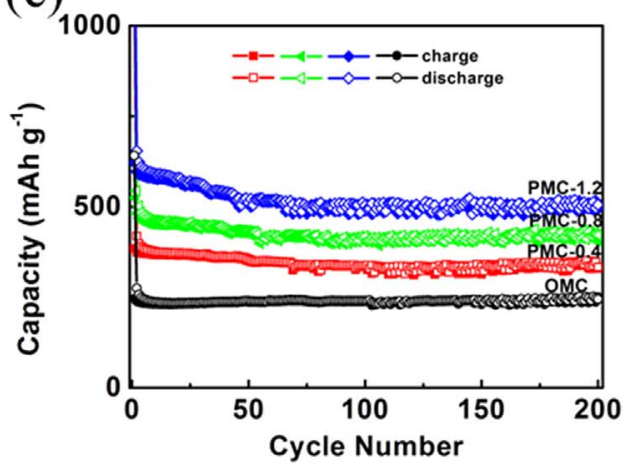

(b)

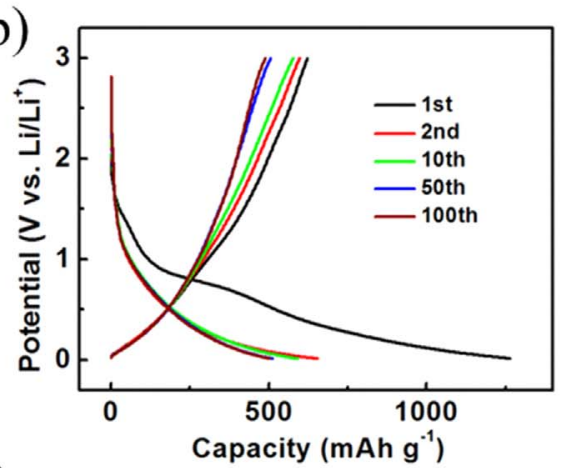

(d)

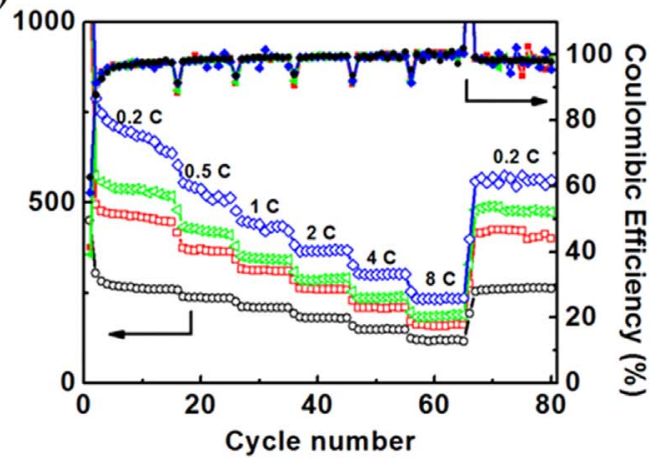

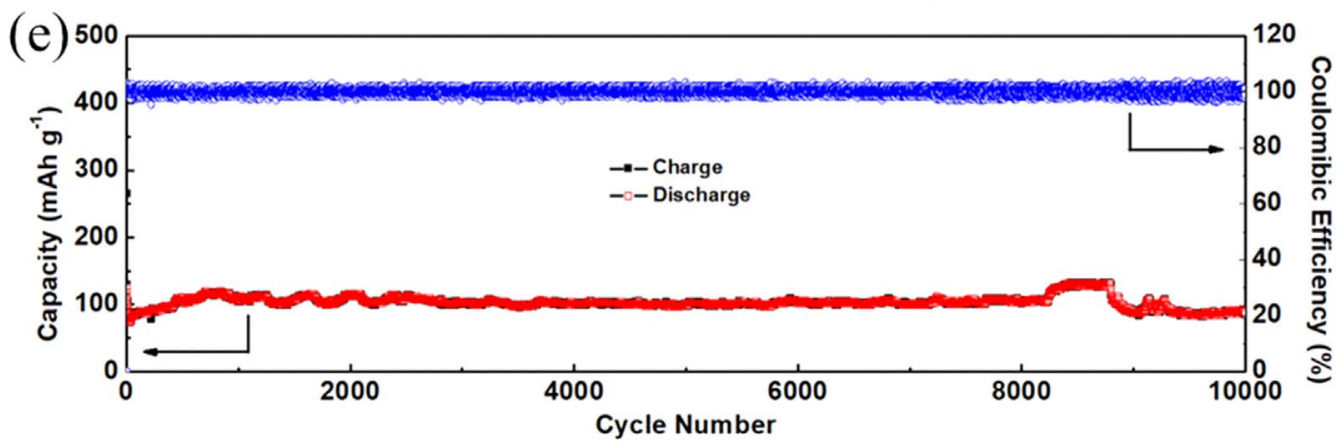

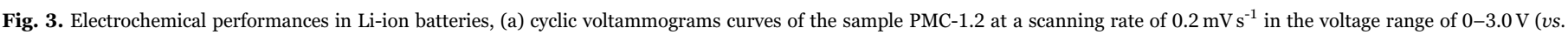

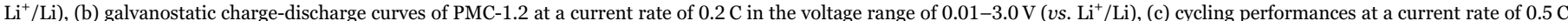

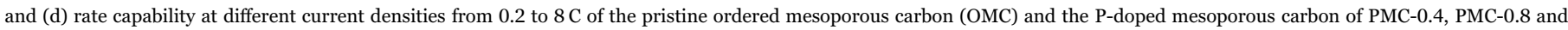
PMC-1.2, (e) long-term cycling performance of PMC-1.2 at a high current rate of $10 \mathrm{Ag}^{-1}$ in the voltage range of $0.01-3.0 \mathrm{~V}\left(v s . \mathrm{Li}^{+} / \mathrm{Li}\right.$ ).

of 1265 and $622 \mathrm{mAh} \mathrm{g}^{-1}$, respectively, corresponding to an initial Coulombic efficiency of $49 \%$. The large irreversible capacity is mainly attributed to the formation of SEI films on the surface of the electrode and the irreversible intercalation of $\mathrm{Li}^{+}$ions [44,45]. The initial discharge and charge capacities of PMC-0.8, PMC-0.4 are 1220 and
$525 \mathrm{~mA} \mathrm{~h} \mathrm{~g}^{-1}, 1053$ and $385 \mathrm{~mA} \mathrm{~h} \mathrm{~g}^{-1}$, corresponding to the coulombic efficiency of 43 and $36 \%$, respectively (Fig. S7). Obviously, the initial capacities of the P-doped mesoporous carbons are much larger than that $\left(643,281 \mathrm{mAh} \mathrm{g}^{-1}\right)$ of the pristine ordered mesoporous carbon (Fig. S7). After the first cycle, the coulombic efficiency of the PMC-1.2

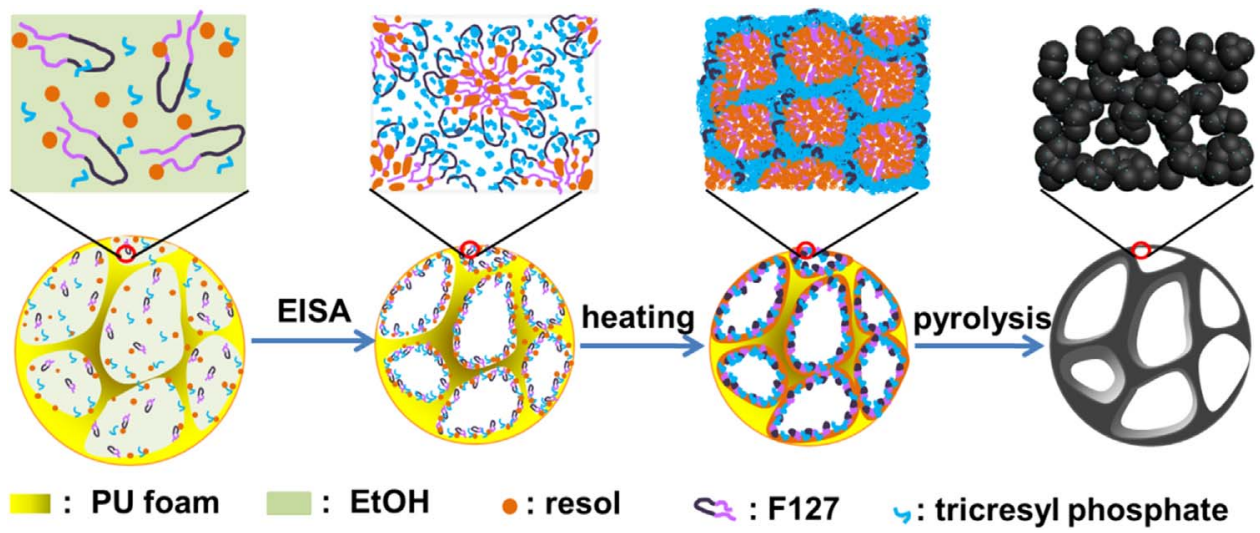

Scheme 1. The formation process of large pore P-doped mesoporous carbons through multi-component co-assembly on the skeletal PU foam. 
(a)

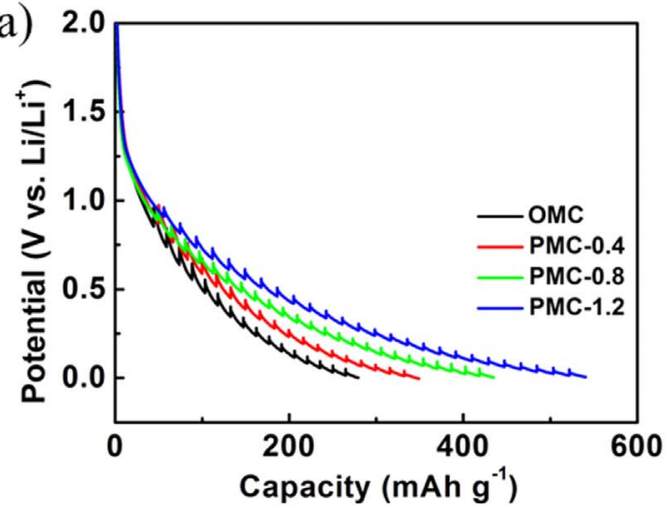

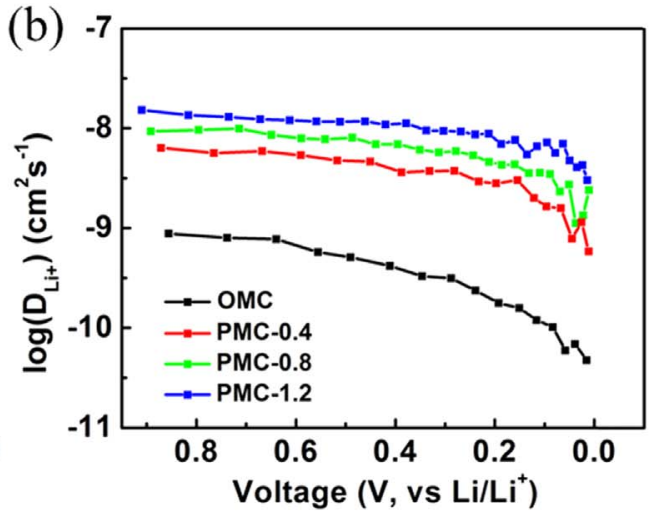

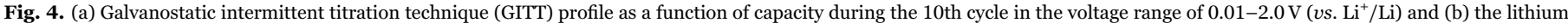

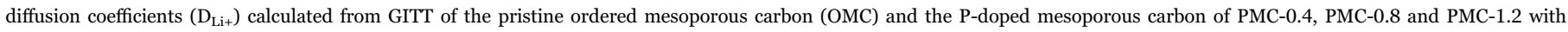
different mole ratio of tricresyl phosphate to phenol.

anode reaches to $92 \%$ for the second cycle and $99 \%$ for the tenth cycle, suggesting an excellent reversible $\mathrm{Li}^{+}$ion intercalation/extraction performance. More significantly, the initial large irreversible capacity could be decreased efficiently after the electrode materials were prelithiated. The initial Coulombic efficiency can be increased to 95.6, 96.2, 96.8\% for PMC-0.4, PMC-0.8 and PMC-1.2, respectively (Fig. S8).

After 200 cycles at $0.5 \mathrm{C}$, the reversible discharge and charge capacities of PMC-0.4, PMC-0.8 and PMC-1.2 can be remained at around 330, 420 and $500 \mathrm{mAh} \mathrm{g}^{-1}$, respectively, much better than that $\left(242 \mathrm{mAh} \mathrm{g}^{-1}\right)$ of the pristine ordered mesoporous carbon (Fig. 3c). Furthermore, the rate capability is also evaluated from 0.2 to $8 \mathrm{C}$ (Fig. 3d). It is clear to see that the PMC-1.2 sample exhibits the best rate capability with high specific capacities of 736, 534, 440, 368, 304, $236 \mathrm{~mA} \mathrm{~h} \mathrm{~g}^{-1}$ at the current densities of $0.2,0.5,1,2,5,8 \mathrm{C}$, respectively. When the current density recovers to $0.2 \mathrm{C}$, a high capacity of $562 \mathrm{mAh} \mathrm{g}^{-1}$ can be restored, further demonstrating a good rate capability. In addition, the PMC-1.2 also possesses significant long-term cycling performance at an ultrahigh current density of $10 \mathrm{Ag}^{-1}$ without obvious capacity decay even after 10,000 cycles (Fig. 3e), suggesting a promising application for fast charging, high capacity, long life batteries.

The high rate performance of the P-doped mesoporous carbons may be explained by the high $\mathrm{Li}^{+}$diffusion coefficient $\left(\mathrm{D}_{\mathrm{Li}+}\right)$, which is further measured by the galvanostatic intermittent titration technique (GITT) (Fig. S9). GITT curves as a function of capacity in the voltage of $0.01-2.0 \mathrm{~V}$ versus $\mathrm{Li} / \mathrm{Li}^{+}$and the corresponding $\mathrm{D}_{\mathrm{Li}+}$ calculated from GITT are shown in Fig. 4. The calculated $\mathrm{D}_{\mathrm{Li}+}$ value of PMC-1.2 is in the range of $1.52 \times 10^{-8}-3.02 \times 10^{-9} \mathrm{~cm}^{2} \mathrm{~s}^{-1}$ at various voltages, which is higher than that of PMC-0.8 $\left(9.29 \times 10^{-9}-1.12 \times 10^{-9} \mathrm{~cm}^{2} \mathrm{~s}^{-1}\right)$ and PMC-0.4 $\left(6.37 \times 10^{-9}-5.82 \times 10^{-10} \mathrm{~cm}^{2} \mathrm{~s}^{-1}\right)$. It is noteworthy that all of the above values are about one or two order of magnitude higher than that of the pristine ordered mesoporous carbon $\left(8.77 \times 10^{-10}-4.74 \times\right.$ $10^{-11} \mathrm{~cm}^{2} \mathrm{~s}^{-1}$ ). This indicates superior diffusion kinetics of $\mathrm{Li}^{+}$in the $\mathrm{P}-$ doped mesoporous carbons, which is attributed to the expanded interlayer distance by P-doping and the larger mesopores, leading to faster $\mathrm{Li}^{+}$diffusion and contributing to the enhanced rate performance.

The significantly improved electrochemical performances can be attributed to the unique nanostructures (Fig. 5a). First, the wellopened mesoporous frameworks composed of small nanoparticles provide efficient contact with the electrolyte, create more active sites for $\mathrm{Li}$ storage, shorten the diffusion distance of $\mathrm{Li}^{+}$ions and accelerate the electron transfer. That can be further confirmed by the electrochemical impedance spectroscopy (EIS) (Fig. 5b). The charge-transfer resistances are calculated to be 78.7, 34.4 and $6.9 \Omega$ for PMC-0.4, PMC0.8 and PMC-1.2, respectively, smaller than that (99.4 $\Omega$ ) of the pristine ordered mesoporous carbon, suggesting a faster $\mathrm{Li}^{+}$ion diffusion and charge transfer. Second, P-doping can enlarge the interlayer space of the carbon, which is beneficial to the $\mathrm{Li}^{+}$ion insertion and extraction. Moreover, the doped $\mathrm{P}$ atoms also introduce more defects in the carbon frameworks, which can also offer more active sites for Li storage, resulting in highly reversible capacities Third, the introduction of phosphorus can significantly improve the electronic conductivity, facilitating fast electron transport. This can be confirmed by the high electronic conductivity of $17,56,420 \mathrm{mS} \mathrm{cm}^{-1}$ for PMC-0.4, PMC-0.8 and PMC-1.2, respectively, which is larger than that $\left(9 \mathrm{mS} \mathrm{cm}^{-1}\right)$ of the pristine ordered mesoporous carbon. It can be attributed to the formation of $\mathrm{P}-\mathrm{C}$ bond which can increase the electron density around the Fermi level [46]. As a result, the improved transport of ion and electron not only enables fast charging and discharging, but also provides long-term cycling stability.
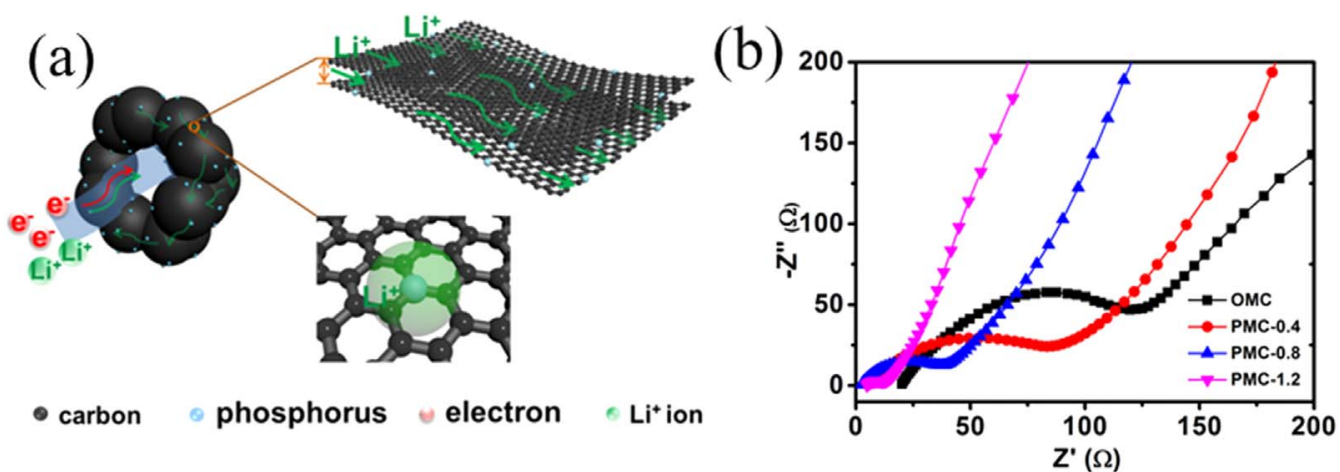

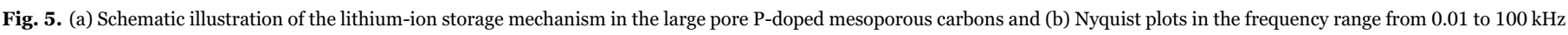

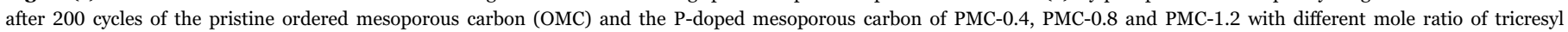
phosphate to phenol. 


\section{Conclusion}

In summary, we have developed a facial method for mass production of large-pore P-doped mesoporous carbons with a high P content and large pore size based on a multi-component co-assembly process. Owing to the hydrophobic character, tricresyl phosphate works as the pore swelling agent, which triggers the micelle structure change during the self-assembly process, leading to the formation of large pore sizes $(6.6-14.2 \mathrm{~nm})$, high surface areas $\left(338-630 \mathrm{~m}^{2} \mathrm{~g}^{-1}\right)$ and small domain sizes. Most importantly, it also functions as the source for P-doping during the high temperature treatment, resulting in a high $\mathrm{P}$ content in the carbon framework (up to 1.90 at\%). As result, the obtained phosphorous-doped mesoporous carbons display much enhanced electrochemical performance with a high reversible specific capacity (above $500 \mathrm{~mA} \mathrm{~h} \mathrm{~g}^{-1}$ after 200 cycles at $0.5 \mathrm{C}$ ), excellent rate capability, and long-term stability (up to 10,000 cycles at high rate of $10 \mathrm{Ag}^{-1}$ ), when being used as an anode for LIBs. We anticipate that this facial and scalable method can be extended to the future development of heteroatom-doped mesoporous carbon materials for energy storage technologies.

\section{Acknowledgment}

This work was supported by the State Key Basic Research Program of the PRC (2018YFA0209401, 2017YFA0207300 and 2016YFA0204000), Key Basic Research Program of Science and Technology Commission of Shanghai Municipality (17JC1400100), and NSFC of China (Grant No. 21733003 and 21603036).

\section{Appendix A. Supporting information}

Supplementary data associated with this article can be found in the online version at doi:10.1016/j.ensm.2019.01.008.

\section{References}

[1] M. Armand, J.M. Tarascon, Nature 451 (2008) 652-657.

[2] B. Dunn, H. Kamath, J.M. Tarascon, Science 334 (2011) 928-935.

[3] G. Derrien, J. Hassoun, S. Panero, B. Scrosati, Adv. Mater. 19 (2007) 2336.

[4] N. Liu, Z. Lu, J. Zhao, M.T. Mcdowell, H.W. Lee, W. Zhao, Y. Cui, Nat. Nanotechnol. 9 (2014) 187-192.

[5] S.Q. Chen, L.F. Shen, P.A. van Aken, J. Maier, Y. Yu, Adv. Mater. 29 (2017) 1605650.

[6] Y.X. Tang, Y.Y. Zhang, J.Y. Deng, D.P. Qi, W.R. Leow, J.Q. Wei, S.Y. Yin, Z.L. Dong, R. Yazami, Z. Chen, X.D. Chen, Angew. Chem. Int. Ed. 53 (2014) 13488-13492.

[7] Y.M. Chen, L. Yu, X.W. Lou, Angew. Chem. Int. Ed. 55 (2016) 5990-5993.

[8] E. Yoo, J. Kim, E. Hosono, H.-S. Zhou, T. Kudo, I. Honma, Nano Lett. 8 (2008) $2277-2282$

[9] B.K. Guo, X.Q. Wang, P.F. Fulvio, M.F. Chi, S.M. Mahurin, X.G. Sun, S. Dai, Adv, Mater. 23 (2011) 4664-4666.

[10] S.S. Li, Y.H. Luo, W. Lv, W.J. Yu, S.D. Wu, P.X. Hou, Q.H. Yang, Q.B. Meng, C. Liu, H.M. Cheng, Adv. Energy Mater. 1 (2011) 486-490.

[11] N. Mahmood, T.Y. Tang, Y.L. Hou, Adv. Energy Mater. 6 (2016) 1600374.
[12] K.T. Lee, J.C. Lytle, N.S. Ergang, S.M. Oh, A. Stein, Adv, Funct. Mater. 15 (2005) $547-556$.

[13] H.J. Yen, H. Tsai, M. Zhou, E.F. Holby, S. Choudhury, A. Chen, L. Adamska, S. Tretiak, T. Sanchez, S. Iyer, Adv, Mater. 28 (2016) 10250-10256.

[14] A.D. Roberts, X. Li, H. Zhang, Chem. Soc. Rev. 43 (2014) 4341-4356.

[15] B. Fang, M.-S. Kim, J.H. Kim, S. Lim, J.-S. Yu, J. Mater. Chem. 20 (2010) 10253-10259.

[16] Y. Ren, A.R. Armstrong, F. Jiao, P.G. Bruce, J. Am. Chem. Soc. 132 (2010) 996-1004.

[17] H. Ming, X.W. Li, Q. Zhou, M.M. Liu, L.L. Su, L.J. Bu, Z.H. Kang, J.W. Zheng, New J. Chem. 37 (2013) 1912-1918.

[18] M.G. Fischer, X. Hua, B.D. Wilts, I. Gunkel, T.M. Bennett, U. Steiner, ACS Appl. Mater. Interfaces 9 (2017) 22388-22397.

[19] D.W.F. Li, M. Liu, G.Q. Lu, H.M. Cheng, Angew. Chem. Int. Ed. 47 (2008) 373-376.

[20] M.S. Kim, D. Bhattacharjya, B.Z. Fang, D.S. Yang, T.S. Bae, J.S. Yu, Langmuir 29 (2013) 6754-6761.

[21] L. Qie, W.M. Chen, Z.H. Wang, Q.G. Shao, X. Li, L.X. Yuan, X.L. Hu, W.X. Zhang, Y.H. Huang, Adv. Mater. 24 (2012) 2047-2050.

[22] J.P. Paraknowitsch, A. Thomas, Energy Environ. Sci. 6 (2013) 2839-2855.

[23] Y. Yan, Y.X. Yin, S. Xin, Y.G. Guo, L.J. Wan, Chem. Commun. 48 (2012) $10663-10665$

[24] Y. Mao, H. Duan, B. Xu, L. Zhang, Y.S. Hu, C.C. Zhao, Z.X. Wang, L.Q. Chen, Y.S. Yang, Energy Environ. Sci. 5 (2012) 7950-7955.

[25] W.H. Li, Z.Z. Yang, M.S. Li, Y. Jiang, X. Wei, X.W. Zhong, L. Gu, Y. Yu, Nano Lett. 16 (2016) 1546-1553.

[26] Z.S. Wu, W. Ren, L. Xu, F. Li, H.M. Cheng, ACS Nano 5 (2011) 5463-5471.

[27] Z. Xing, Z.C. Ju, Y.L. Zhao, J.L. Wan, Y.B. Zhu, Y.H. Qiang, Y.T. Qian, Sci. Rep. 6 (2016) 26146.

[28] D.S. Yang, D. Bhattacharjya, M.Y. Song, J.-S. Yu, Carbon 67 (2014) 736-743.

[29] Y.P. Zhu, Y.L. Liu, Y.P. Liu, T.Z. Ren, T.H. Chen, Z.Y. Yuan, ChemCatChem 7 (2015) 2903-2909.

[30] J.Q. Wang, Z.Z. Yang, F.S. Pan, X.W. Zhong, X.W. Liu, L. Gu, Y. Yu, RSC Adv. 5 (2015) 55136-55142.

[31] D.-S. Yang, D. Bhattacharjya, S. Inamdar, J. Park, J.-S. Yu, J. Am. Chem. Soc. 134 (2012) 16127-16130.

[32] C.Z. Zhang, N. Mahmood, H. Yin, F. Liu, Y.L. Hou, Adv. Mater. 25 (2013) $4932-4937$.

[33] Y. Meng, D. Gu, F.Q. Zhang, Y.F. Shi, H.F. Yang, Z. Li, C.Z. Yu, B. Tu, D.Y. Zhao, Angew. Chem. Int. Ed. 44 (2005) 7053-7059.

[34] Z.F. Li, C. Bommier, Z.S. Chong, Z.L. Jiang, T.W. Surta, X.F. Wang, Z.Y. Xing, J.C. Neuefeind, W.F. Stickle, M. Dolgos, P.A. Greaney, X.L. Ji, Adv. Energy Mater (2017) 1602894

[35] F. Wu, R.Q. Dong, Y. Bai, Y. Li, G.H. Chen, Z.H. Wang, C. Wu, ACS Appl. Mater. Interfaces 10 (2018) 21335-21342.

[36] J.C. Han, A.P. Liu, J.Q. Zhu, M.L. Tan, H.P. Wu, Appl. Phys. A 88 (2007) 341-345.

[37] M. Wang, Z.Z. Yang, W.H. Li, L. Gu, Y. Yu, Small 19 (2016) 2559-2566.

[38] N. Wang, Q.L. Liu, B.Y. Sun, J.J. Gu, B.X. Yu, W. Zhang, D. Zhang, Sci. Rep. 8 (2018) 9934.

[39] L. Qie, W. Chen, X. Xiong, C. Hu, F. Zou, P. Hu, Y. Huang, Adv. Sci. 2 (2015) 1500195.

[40] K. Tang, L.-J. Fu, R.J. White, L.-H. Yu, M.M. Titirici, M. Antonietti, J. Maier, Adv. Energy Mater. 2 (2012) 873-877.

[41] P. Guo, H. Song, X. Chen, Electrochem. Commun. 11 (2009) 1320-1324.

[42] N. Mahmood, C. Zhang, Y. Hou, Small 9 (2013) 1321-1328.

[43] F.D. Han, Y.J. Bai, R. Liu, B. Yao, Y.X. Qi, N. Lun, J.X. Zhang, Adv. Energy Mater. 1 (2011) 798-801.

[44] C. Yu, M. Chen, X.J. Li, C.T. Zhao, L.L. He, J.S. Qiu, J. Mater. Chem. A 3 (2015) 5054-5059.

[45] S. Yang, X. Feng, L. Zhi, Q. Cao, J. Maier, K. Müllen, Adv. Mater. 22 (2010) $838-842$.

[46] F. Wu, R.Q. Dong, Y. Bai, Y. Li, G.H. Chen, Z.H. Wang, C. Wu, ACS Appl. Mater. Interfaces 10 (2018) 21335-21342. 